\title{
The new Senate
}

\section{The organisers are to be congratulated on achieving this, as history has repeatedly shown us that human beings seem to focus more on their differences than on their combined aims.}

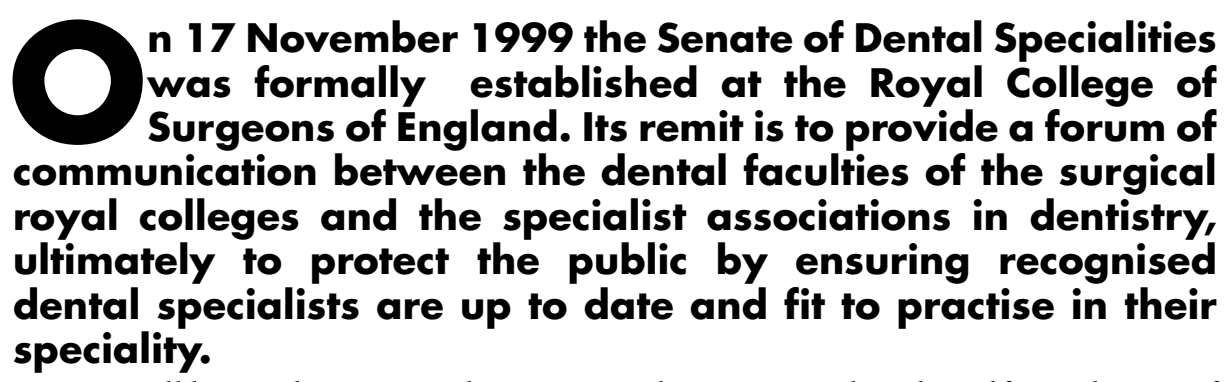

As we all know there is a real concern at the moment that the self-regulation of professions is not simply an attempt for professionals to protect themselves from failure to deliver ethical and appropriate service for their customers/patients. Dentistry has always been fairly pro-active at providing its own self-regulation, and the Senate of Dental Specialities is yet another example of this. The membership sounds impressive, consisting of the deans of the dental faculties of the surgical royal colleges of England, Edinburgh, Glasgow and Ireland as well as representatives of the existing specialist associations and new dental specialities as they come into existence. The Senate will also contain the chairmen of various postgraduate education and training committees and observers from the General Dental Council.

This all fits in well with clinical governance, continuing professional development and lifelong learning. Perhaps the most remarkable aspect of the whole enterprise is the fact it has happened at all and that so many different groups have agreed to form a single group with a single main objective. The organisers are to be congratulated on achieving this, as history has repeatedly shown us that human beings seem to focus more on their differences than on their combined aims.

Yet, from the press release to mark this occasion, we are not given very much information on exactly what the Senate is going to do - apart from meet twice a year. The intriguing phrase in the statement of aims is 'to promote the highest standards of professional practice in the dental specialities by providing a forum of communication'. What exactly does that mean? How does it differ from the activities of the General Dental Council? What does the Senate offer us that we do not already have, apart from the fact the various dental specialities are talking to each other in public?

The answer lies in one word tucked quietly away in one of the objectives culture. The objective states 'To develop a framework and a culture within which all dental specialists can demonstrate that they are keeping themselves up to date and remain fit to practice within their chosen field.' What the Senate is trying to achieve is a culture of agreement among specialists in both hospital and practice as to what quality dental care is and what agreed standards will ensure that specialists keep up to date. It hopes to achieve this by setting the same standards for all specialists, by adopting common audit and peer review, and by ensuring that specialists in any particular speciality talk a common language.

It is this blend of thinking and communication between specialisation in hospital and practice that is so important. In the past the recognised dental specialities have tended to operate solely from a hospital base, creating difficulties in both training for practitioners and access for patients. The inclusion of the specialist societies in the Senate should help ensure realistic development for practitioners, especially those societies with a strong general practitioner base.

Will it work? Only time will tell. Obviously, the ultimate success of the venture lies with the specialists themselves and their acceptance of common agreed standards and hopefully it will open the door to similar thinking in other areas of dentistry. 